Article

\title{
Synthesis and Characterization of Barium Hexafluoridoosmates
}

\author{
Sergei I. Ivlev ${ }^{1}$, Antti J. Karttunen ${ }^{2}$, Magnus R. Buchner ${ }^{1}$, Matthias Conrad ${ }^{1}$, \\ Roman V. Ostvald ${ }^{3}$ and Florian Kraus ${ }^{1, *}$ \\ 1 Fachbereich Chemie, Philipps-Universität Marburg, 35032 Marburg, Germany; \\ sergei.ivlev@chemie.uni-marburg.de (S.I.I.); Magnus.buchner@chemie.uni-marburg.de (M.R.B.); \\ conradm@Staff.Uni-Marburg.DE (M.C.) \\ 2 Department of Chemistry and Materials Science, Aalto University, 00076 Aalto, Finland; \\ antti.j.karttunen@iki.fi \\ 3 Institute of Applied Physics and Technology, Tomsk Polytechnic University, Tomsk 634050, Russia; \\ tpurom@mail.ru \\ * Correspondence: florian.kraus@chemie.uni-marburg.de; Tel.: +49-6421-28-26668
}

Received: 27 November 2017; Accepted: 24 December 2017; Published: 29 December 2017

\begin{abstract}
Two barium hexafluoridoosmates, $\mathrm{Ba}\left(\mathrm{OsF}_{6}\right)_{2}$ and $\mathrm{BaOsF}_{6}$, were synthesized and were characterized for the first time using $\mathrm{X}$-ray powder and single crystal diffraction, IR spectroscopy, as well as NMR spectroscopy in anhydrous hydrogen fluoride. $\mathrm{Ba}\left(\mathrm{OsF}_{6}\right)_{2}$ crystallizes in the space group type $P 2_{1} / c$ with the cell parameters $a=6.4599(4), b=10.7931(8), c=14.7476(10) \AA$, $\beta=115.195(5)^{\circ}, V=930.42(12) \AA^{3}, Z=4$ at $293 \mathrm{~K}$. BaOsF 6 crystallizes in the space group type $R \overline{3}$ with the cell parameters $a=7.3286(10), c=7.2658(15) \AA, V=337.95(12) \AA^{3}, Z=3$ at $100 \mathrm{~K}$. Additionally, we have obtained the compounds $\mathrm{Ba}\left(\mathrm{OsF}_{6}\right)_{2} \cdot 3 \mathrm{BrF}_{3}, \mathrm{Ba}\left(\mathrm{OsF}_{6}\right)_{2} \cdot \mathrm{HF}, \mathrm{Ba}\left(\mathrm{OsF}_{6}\right)_{2} \cdot 6 \mathrm{H}_{2} \mathrm{O}$ from the respective solvents, and $\mathrm{Ba}\left(\mathrm{OsF}_{6}\right)_{2}$.
\end{abstract}

Keywords: osmium; fluorides; bromine trifluoride; crystal structure

\section{Introduction}

The fluoroanions of osmium, $\mathrm{OsF}_{6}{ }^{-}$and $\mathrm{OsF}_{6}{ }^{2-}$, are known since the 1950s. The first compounds containing these species were prepared by Hepworth and coworkers [1]: $\operatorname{MOsF}_{6}(M=\mathrm{Li}, \mathrm{K}, \mathrm{Rb}$, Cs, $\mathrm{Ag})$ and $\mathrm{M}_{2} \mathrm{OsF}_{6}(M=\mathrm{K}, \mathrm{Cs})$, and were later characterized by various techniques, such as IR spectroscopy [2-6] and X-ray diffraction [7-9]. Both anions can be of relevance for the urban mining processes $[10,11]$ and the analytical chemistry of osmium $[12,13]$. Furthermore, the recent investigations showed that both species can be treated as model systems for investigating spin-orbit entangled phenomena in complexes with $\mathrm{Os}^{4+}$ and $\mathrm{Os}^{5+}$ atoms [14].

To the best of our knowledge, no alkaline-earth metal compounds with hexafluoridoosmate ions have been synthesized so far. Here, we present our results on the syntheses and characterization of the two barium hexafluoridoosmates: $\mathrm{BaOsF}_{6}$ and $\mathrm{Ba}\left(\mathrm{OsF}_{6}\right)_{2}$. Also, we briefly report three derivatives of barium hexafluoridoosmate $(\mathrm{V})$, which are solvates: " $\mathrm{Ba}\left(\mathrm{OsF}_{6}\right)_{2} \cdot n \mathrm{BrF}_{3}$ ", "Ba( $\left(\mathrm{OsF}_{6}\right)_{2} \cdot n \mathrm{HF}^{\prime}$, and $\mathrm{Ba}\left(\mathrm{OsF}_{6}\right)_{2} \cdot 6 \mathrm{H}_{2} \mathrm{O}$.

\section{Materials and Methods}

General: All of the operations with the compounds were carried out in an atmosphere of dry and purified argon (Westfalen AG, Münster, Germany), so that a possible contact of the substance with moisture or air was minimized $\left(\mathrm{O}_{2}<1 \mathrm{ppm}, \mathrm{H}_{2} \mathrm{O}<1 \mathrm{ppm}\right)$. $\mathrm{BrF}_{3}$ was synthesized by slowly passing gaseous fluorine through liquid bromine in an FEP U-tube reactor. Anhydrous HF was additionally dried by storing it over $\mathrm{K}_{2} \mathrm{NiF}_{6} \cdot \mathrm{BaF}_{2}$ and $\mathrm{Os}$ were used without additional purification. 
Preparation of $\mathrm{Ba}\left(\mathrm{OsF}_{6}\right)_{2}: \mathrm{BaF}_{2}(0.1137 \mathrm{~g}, 0.65 \mathrm{mmol}, 1.00$ equiv.) and $\mathrm{Os}(0.2466 \mathrm{~g}, 1.30 \mathrm{mmol}$, 1.00 equiv.) were placed in an FEP tube and were layered with large excess of bromine trifluoride ( $1 \mathrm{~mL}, 2.8 \mathrm{~g}, 20.45 \mathrm{mmol}, 69.13$ equiv.). The FEP tube was closed with a PFA valve and was allowed to stay for $24 \mathrm{~h}$ at $120^{\circ} \mathrm{C}$ with occasional shaking. After that the excess of $\mathrm{BrF}_{3}$ was pumped off at room temperature, the tube was flushed with argon several times and the compound was stored in a glove box with an inert atmosphere in a Teflon container. The total yield of dry product was $0.463 \mathrm{~g}$ (0.62 mmol, $95.7 \%$ of theory).

Preparation of $\mathrm{BaOsF}_{6}: \mathrm{Ba}\left(\mathrm{OsF}_{6}\right)_{2}(0.1334 \mathrm{~g}, 0.65 \mathrm{mmol}, 1.00$ equiv.) was placed in an Teflon beaker and was dissolved in $\sim 5 \mathrm{~mL}$ of $\mathrm{H}_{2} \mathrm{O}(5 \mathrm{~g}, 277 \mathrm{mmol}, 517$ equiv.). The beaker was left on a hot plate set up to $80^{\circ} \mathrm{C}$. After complete evaporation of water, the product was transferred into a Teflon container and further handled on air. The total yield of the dry product was $0.080 \mathrm{~g}$ ( $80.9 \%$ of theory), which corresponds to $0.064 \mathrm{~g}$ of $\mathrm{BaOsF}_{6}$ and $0.016 \mathrm{~g}$ of $\mathrm{OsO}_{2}$, according to Reaction 2.

Preparation of $\mathrm{Ba}\left(\mathrm{OsF}_{6}\right)_{2} \cdot 3 \mathrm{BrF} 3: \mathrm{Ba}\left(\mathrm{OsF}_{6}\right)_{2}(0.05 \mathrm{~g}, 0.067 \mathrm{mmol})$ was placed in an FEP tube and covered with a small amount of $\mathrm{BrF}_{3}(\sim 0.1 \mathrm{~mL})$. The FEP tube was heated to $120^{\circ} \mathrm{C}$ and then allowed to cool down to room temperature on air. Upon cooling the crystals of the target product were formed in the tube and were then picked directly out of $\mathrm{BrF}_{3}$. The mass of the product was not determined due to the presence of the excess solvent.

Preparation of $\mathrm{Ba}\left(\mathrm{OsF}_{6}\right)_{2} \cdot \mathrm{HF}: \mathrm{Ba}\left(\mathrm{OsF}_{6}\right)_{2}(0.05 \mathrm{~g}, 0.067 \mathrm{mmol})$ was placed in an FEP tube. A small amount of $\mathrm{HF}(\sim 0.1 \mathrm{~mL})$ was distilled at $-196{ }^{\circ} \mathrm{C}$ into the tube and then was heated up to $50{ }^{\circ} \mathrm{C}$ in order to dissolve the hexafluoridoosmate. Then, the FEP tube was allowed to cool down to room temperature on air. Upon cooling the crystals of the target product were formed in the tube and were then picked directly out of HF. The mass of the product was not determined due to the presence of the excess solvent.

Preparation of $\mathrm{Ba}\left(\mathrm{OsF}_{6}\right)_{2} \cdot 6 \mathrm{H}_{2} \mathrm{O}: \mathrm{Ba}\left(\mathrm{OsF}_{6}\right)_{2}(0.05 \mathrm{~g}, 0.067 \mathrm{mmol})$ was placed on an FEP plate. A few droplets of water were placed on the substance. Then, the plate was allowed to stay in the air flow of the laboratory ventilation to facilitate the drying process without heating. When a significant amount of water was evaporated and the crystals of the target compound appeared, the plate was transferred into a refrigerator and was kept there at $-35{ }^{\circ} \mathrm{C}$. Storage at room temperature leads eventually to the decomposition of the product into $\mathrm{BaOsF}_{6}$ and the black powder. The mass of the product was not determined due to the presence of the excess solvent.

Density Measurement Details: The density of $\mathrm{Ba}\left(\mathrm{OsF}_{6}\right)_{2}$ was measured using the automated gas displacement pycnometry system AccuPyc II 1340 (Micromeritics, Aachen, Germany) using a calibrated $0.1 \mathrm{~cm}^{3}$ sample holder and helium as the gas being displaced. The number of preliminary purges was set to 30 , while the subsequent density measurements were done 50 times with further averaging.

Single Crystal X-ray Diffraction: Structure analysis was carried out using a Stoe IPDS2 (Stoe, Darmstadt, Germany) or IPDS2T diffractometer IPDS2 (Stoe, Darmstadt, Germany) with monochromated molybdenum radiation (Mo-K $\mathrm{K}_{\alpha}, \lambda=0.71073 \AA$, a plane graphite monochromator) and an image plate detector. Evaluation and integration of the diffraction data was carried out using the Stoe X-Area software suite (v1.69) [15], and an empirical absorption correction was applied. The structure was solved using direct methods (SHELXT, 2014/4) [16] and refined against $F^{2}$ (SHELXL) [17]. All of the atoms were located by Difference Fourier synthesis. Further details of the crystal structure investigation may be obtained from the Fachinformationszentrum Karlsruhe, 76344 Eggenstein-Leopoldshafen, Germany (Fax: +49-7247-808-666; E-Mail: crysdata@fiz-karlsruhe.de, http://www.fiz-karlsruhe.de/requestfordepositeddata.html) on quoting the depository numbers $\mathrm{Ba}\left(\mathrm{OsF}_{6}\right)_{2}: \mathrm{CSD}-433821, \mathrm{BaOsF}_{6}: \mathrm{CSD}-433819, \mathrm{Ba}\left(\mathrm{OsF}_{6}\right)_{2} \cdot 6 \mathrm{H}_{2} \mathrm{O}: \mathrm{CSD}-433821$.

$X$-ray Powder Diffractometry: Powder X-ray diffraction patterns were obtained with a Stadi-MP diffractometer (Stoe, Darmstadt, Germany) using $\mathrm{Cu}-\mathrm{K}_{\alpha 1}$ radiation, a germanium monochromator, and a Mythen $1 \mathrm{~K}$ detector (the resolution is $0.015 \AA$ ). A sample of $\mathrm{Ba}\left(\mathrm{OsF}_{6}\right)_{2}$ was filled into a flame-dried quartz capillary $(\varnothing 0.3 \mathrm{~mm}$ ) inside a glove box, and then sealed. The measurement was carried out in the 2theta range from 10 to $75^{\circ}$ with a detector step of $0.3^{\circ}$ and collection time of $250 \mathrm{~s}$. The data 
were handled and indexed using the WinXPOW software (v3.07) [18]. Le Bail profile fitting, space group assignment and Rietveld refinement were done in the Jana2006 software [19]. The structure solution prior to the Rietveld refinement was done using the SUPERFLIP algorithm [20] implemented in Jana2006. Barium and osmium atoms were refined isotropic, whereas the displacement parameters of the fluorine atoms were fixed.

NMR spectroscopy: ${ }^{1} \mathrm{H}$ and ${ }^{19} \mathrm{~F}$ NMR spectra were recorded on a Bruker Avance III HD 300 NMR spectrometer (Bruker BioSpin GmbH, Rheinstetten, Germany). ${ }^{1} \mathrm{H}$ NMR spectroscopy $(300 \mathrm{MHz}$, Bruker BioSpin $\mathrm{GmbH}$, Rheinstetten, Germany) used $\mathrm{SiMe}_{4}$ and ${ }^{19} \mathrm{~F}$ NMR spectroscopy (293 MHz) used neat $\mathrm{CFCl}_{3}$ as an external reference, respectively. Samples were prepared by condensing liquid anhydrous hydrogen fluoride onto $\mathrm{Ba}\left(\mathrm{OsF}_{6}\right)_{2}$ at $-196^{\circ} \mathrm{C}$ in $3 \mathrm{~mm}$ FEP tubes, which were sealed with a heat gun and these were subsequently placed in standard $5 \mathrm{~mm}$ glass NMR tubes. Chemical shifts are given for $300 \mathrm{~K}$ at 1.31 bar hydrogen fluoride vapor pressure. $\mathrm{Ba}\left(\mathrm{OsF}_{6}\right)_{2}:{ }^{19} \mathrm{~F}(\mathrm{aHF}): \delta=149.03\left(\mathrm{OsF}_{6}{ }^{-}\right)$.

IR Spectroscopy: The IR spectra of $\mathrm{BaOsF}_{6}$ were recorded using a Bruker Alpha FTIR spectrometer (Bruker Optik GmbH, Rosenheim, Germany) under an Ar atmosphere. The data were handled in the OPUS software package [21].

Computational Details: The structural and spectroscopic properties of $\mathrm{Ba}\left(\mathrm{OsF}_{6}\right)_{2}$ and $\mathrm{BaOsF}_{6}$ were investigated using the CRYSTAL14 program package (CRYSTAL14) [22,23]. Both the atomic positions and the lattice parameters were fully optimized using the PBE0 hybrid density functional method $[24,25]$. Split-valence + polarization (SVP) level basis sets, as derived from the molecular Karlsruhe basis sets [26], were applied for all the atoms (see Supporting information for additional basis set details). The reciprocal space was sampled using a compound-dependent Monkhorst-Pack-type k-point grid: $6 \times 4 \times 2$ for $\mathrm{Ba}\left(\mathrm{OsF}_{6}\right)_{2}$ and $8 \times 8 \times 8$ for $\mathrm{BaOsF}_{6}$ [27]. For the evaluation of the Coulomb and exchange integrals (TOLINTEG), tight tolerance factors of $8,8,8,8$, and 16 were used. Default optimization convergence thresholds and DFT integration grids were applied in all calculations. For $\mathrm{Ba}\left(\mathrm{OsF}_{6}\right)_{2}$, we carried out spin-polarized calculations. We set the spin orientations for the crystallographically inequivalent osmium atoms so that we obtained an antiferromagnetic ordering. The harmonic vibrational frequencies [28,29] and IR intensities [30] were obtained by using the computational schemes that were implemented in CRYSTAL. The IR spectrum of $\mathrm{BaOsF}_{6} \mathrm{Was}$ broadened by using Lorenzian peak profile and FWHM of $8 \mathrm{~cm}^{-1}$.

\section{Results}

\subsection{Synthesis of Barium Hexafluoridoosmate(V)}

We used bromine trifluoride as the oxidizing and fluorinating medium for the synthesis of $\mathrm{Ba}\left(\mathrm{OsF}_{6}\right)_{2}$ [1]. A stoichiometric mixture of $\mathrm{BaF}_{2}$ and osmium metal was loaded into a vessel made of FEP (perfluorinated ethylene-propylene copolymer) and covered with an excess of $\mathrm{BrF}_{3}$. The tightly closed vessel was heated up to $120^{\circ} \mathrm{C}$ and kept at this temperature for $24 \mathrm{~h}$. Under these conditions, the oxidation of osmium slowly proceeds, according to the following Equation (1):

$$
3 \mathrm{BaF}_{2}+6 \mathrm{Os}+10 \mathrm{BrF}_{3} \rightarrow 3 \mathrm{Ba}\left(\mathrm{OsF}_{6}\right)_{2}+5 \mathrm{Br}_{2} .
$$

After cooling down to room temperature the FEP vessel contained a clear green-brown solution. The excess of bromine trifluoride was pumped off yielding a fine pale-pink powder with a mass corresponding to the composition of $\mathrm{Ba}\left(\mathrm{OsF}_{6}\right)_{2}$ (see experimental details).

\subsection{Synthesis of Barium Hexafluoridoosmate(IV)}

$\mathrm{BaOsF}_{6}$ was obtained by dissolving $\mathrm{Ba}\left(\mathrm{OsF}_{6}\right)_{2}$ in water and evaporating the solution at $80{ }^{\circ} \mathrm{C}$. Upon the addition of water the solution became pale yellow and small gas bubbles appeared, which was reported to be $\mathrm{OsO}_{4}$ [1]. When the water was completely evaporated, a mixture of a black powder with colorless crystals was obtained. The nature of the black powder is yet unclear, however, the experimental data indicate that osmium(IV) dioxide formed due to the disproportionation 
of the $\mathrm{OsF}_{6}{ }^{-}$anion in aqueous solution. The tentative reaction can be described by the following Equation (2):

$$
2 \mathrm{Ba}\left(\mathrm{OsF}_{6}\right)_{2}+6 \mathrm{H}_{2} \mathrm{O} \rightarrow 2 \mathrm{BaOsF}_{6}+\mathrm{OsO}_{4}+\mathrm{OsO}_{2}+12 \mathrm{HF}
$$

\subsection{Attempts to Grow Single Crystals of $\mathrm{Ba}\left(\mathrm{OsF}_{6}\right)_{2}$}

As no single crystals of barium hexafluoridoosmate $(\mathrm{V})$ were obtained after evaporation of bromine trifluoride, we attempted to grow them using the following solvents: $\mathrm{BrF}_{3}, \mathrm{HF}$, and $\mathrm{H}_{2} \mathrm{O}$. However, in all of the cases, solvent molecules were retained in the crystal lattice forming solvates.

\subsubsection{Bromine Trifluoride}

If $\mathrm{BrF}_{3}$ is not evaporated completely, the growth of large prismatic light-green crystals can be observed. The compound was identified as a $\mathrm{BrF}_{3}$ solvate of $\mathrm{Ba}\left(\mathrm{OsF}_{6}\right)_{2}$. However, we faced certain difficulties with the structure elucidation (see Section 3.3). Thus, details on this compound will be reported elsewhere.

\subsubsection{Anhydrous Hydrogen Fluoride (aHF)}

$\mathrm{Ba}\left(\mathrm{OsF}_{6}\right)_{2}$ was found to be well soluble in aHF forming a reddish solution and yielding pink crystals after evaporation. However, the resulting compound seems to retain at least one molecule of $\mathrm{HF}$, and can be described with a preliminary formula " $\mathrm{Ba}\left(\mathrm{OsF}_{6}\right)_{2} \cdot \mathrm{HF}$.

\subsubsection{Water}

It was noticed that during the synthesis of $\mathrm{BaOsF}_{6}$, the hydrolysis of $\mathrm{Ba}\left(\mathrm{OsF}_{6}\right)_{2}$ does not happen immediately. If water is quickly evaporated from a large surface of the solution without heating, the residue is a thin colorless film consisting of small crystals. According to single crystal diffraction data, they belong to another compound: $\mathrm{Ba}\left(\mathrm{OsF}_{6}\right)_{2} \cdot 6 \mathrm{H}_{2} \mathrm{O}$.

\section{Discussion}

\subsection{Barium Hexafluoridoosmate(V)}

No single crystals of $\mathrm{Ba}\left(\mathrm{OsF}_{6}\right)_{2}$ have been obtained so far. Despite that it was possible to successfully solve its crystal structure on the basis of powder X-ray diffraction data. The powder diffraction pattern of $\mathrm{Ba}\left(\mathrm{OsF}_{6}\right)_{2}$ recorded in a sealed quartz capillary is shown in Figure 1 . The structure solution was carried out using the SUPERFLIP algorithm [31] and implemented in the Jana2006 software [32]. Due to the instability of the Rietveld refinement only the Os and the Ba atoms could be refined isotropic. The thermal displacement parameters of the fluorine atoms had to be fixed.

Barium bis(hexafluoridoosmate $(\mathrm{V}))$ crystallizes in the monoclinic primitive space group type $P 2_{1} / c$ (No. 14) with the cell parameters $a=6.4599(4), b=10.7931(8), c=14.7476(10) \AA, \beta=115.195(5)^{\circ}$, $V=930.42(12) \AA^{3}$, and $Z=4$ at $293 \mathrm{~K}$. The pycnometric density equals $5.20 \pm 0.04 \mathrm{~g} / \mathrm{cm}^{3}$, which is sufficiently close to the theoretical value of $5.3236 \mathrm{~g} / \mathrm{cm}^{3}$. The crystal structure of $\mathrm{Ba}\left(\mathrm{OsF}_{6}\right)_{2}$ is shown in Figure 2; its asymmetric unit is shown in Figure 3.

All atoms in the crystal lattice of $\mathrm{Ba}\left(\mathrm{OsF}_{6}\right)_{2}$ occupy the general $4 e$ Wyckoff position. The barium cation is coordinated by nine fluorine atoms belonging to nine different $\mathrm{OsF}_{6}{ }^{-}$anions resulting in a tricapped trigonal prismatic coordination sphere. 


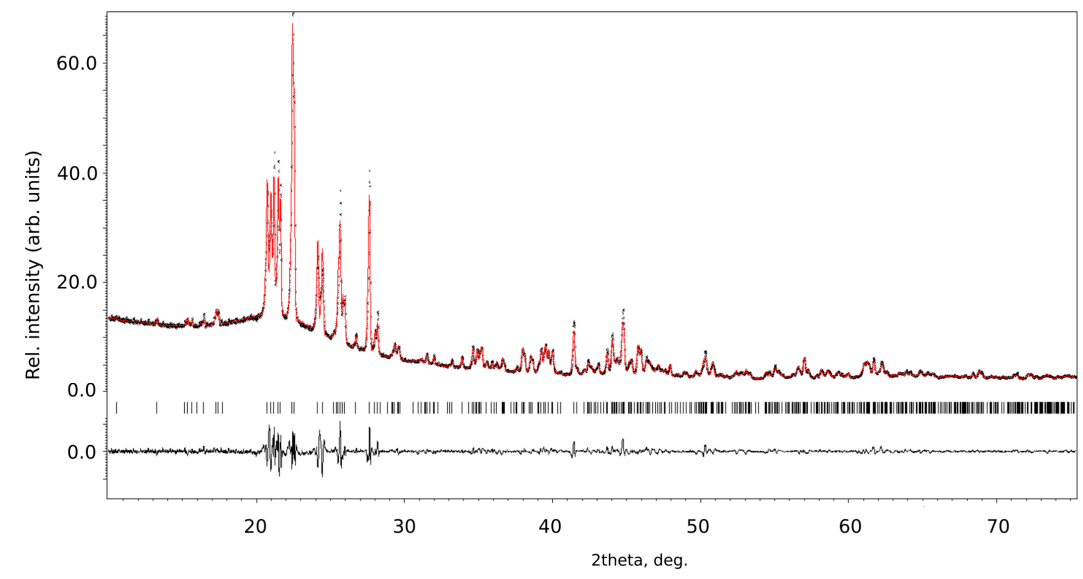

Figure 1. Powder $\mathrm{X}$-ray diffraction pattern (at $293 \mathrm{~K}$ ) of $\mathrm{Ba}\left(\mathrm{OsF}_{6}\right)_{2}$ : the experimental data (black crosses), the Rietveld profile (red), and the differential profile (bottom, black). The calculated reflection positions for $\mathrm{Ba}\left(\mathrm{OsF}_{6}\right)_{2}$ are shown as black ticks. $R_{\mathrm{p}}=0.0343, w R_{\mathrm{p}}=0.0492$.

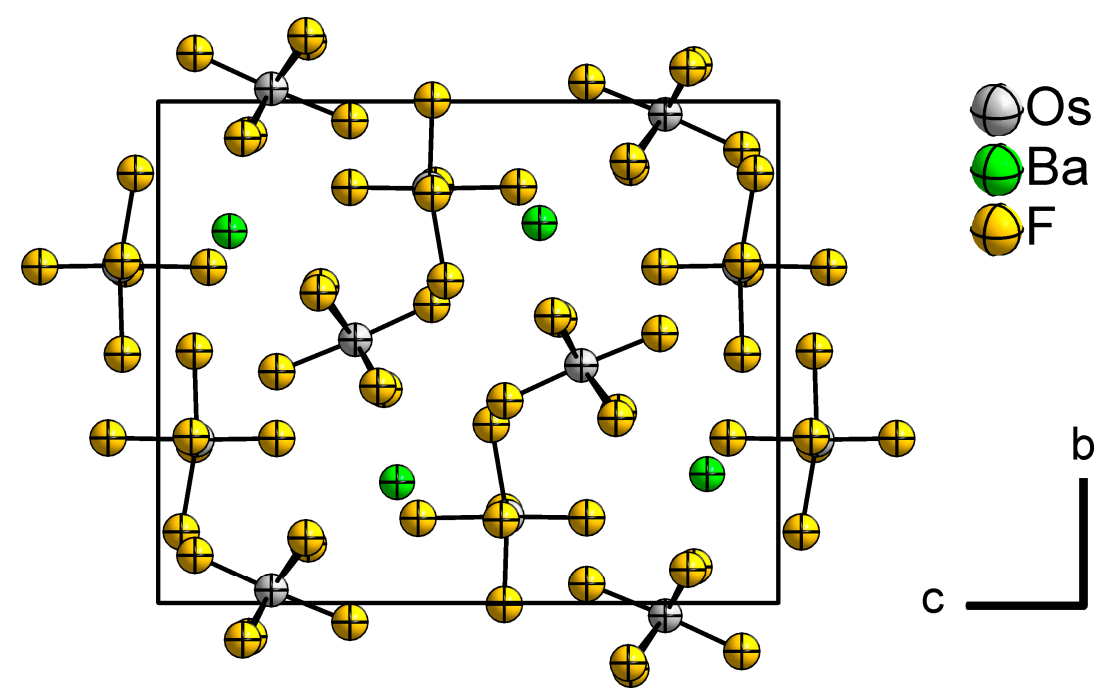

Figure 2. The crystal structure of $\mathrm{Ba}\left(\mathrm{OsF}_{6}\right)_{2}$ (projection along $a$-axis). Atoms are shown with isotropic displacement parameters, $\mathrm{F}$ atoms with fixed ones.

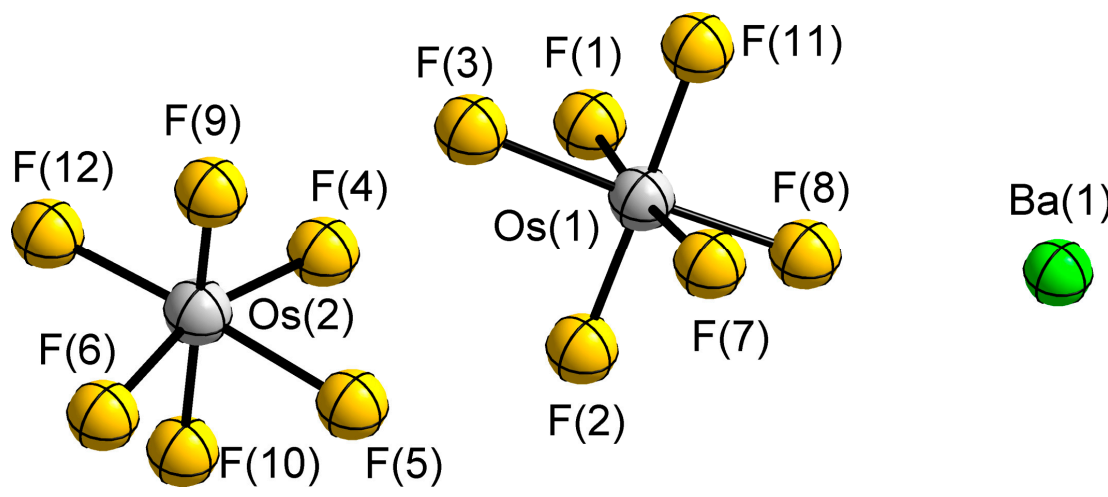

Figure 3. Asymmetric unit of $\mathrm{Ba}\left(\mathrm{OsF}_{6}\right)_{2}$. Atoms are shown with isotropic displacement parameters, F atoms with fixed ones. 
Due to the low precision in the determination of the bond lengths and angles, it was not possible to carry out a detailed analysis of the structural features in $\mathrm{Ba}\left(\mathrm{OsF}_{6}\right)_{2}$. For further information, we also optimized the structure with quantum chemical methods (DFT-PBE0/SVP level of theory). Some selected experimental and calculated values are given in Table 1, together with the corresponding values in $\mathrm{KOsF}_{6}$, which is a well characterized compound with the $\mathrm{OsF}_{6}{ }^{-}$anion [8]. The experimental and theoretical lattice constants are in good agreement (differences less than 1.3\%). The calculated bond lengths and angles correspond to the experimental values within the $3 \sigma$ criterion. The crystallographic details of $\mathrm{Ba}\left(\mathrm{OsF}_{6}\right)_{2}$ are given in Table 2 .

Table 1. Selected crystallographic data for $\mathrm{Ba}\left(\mathrm{OsF}_{6}\right)_{2}$ and $\mathrm{KOsF}_{6}$ [8].

\begin{tabular}{cccc}
\hline \multirow{2}{*}{ Value } & \multicolumn{2}{c}{$\mathrm{Ba}\left(\mathrm{OsF}_{\mathbf{6}}\right)_{\mathbf{2}}{ }^{*}$} & \multirow{2}{*}{ KOsF $_{\mathbf{6}}$} \\
\cline { 2 - 3 } & Exp. & DFT-PBE0 & \\
\hline$a, \AA$ & $6.4599(4)$ & 6.46 & \\
$b, \AA$ & $10.7931(8)$ & 10.65 & \\
$c, \AA$ & $14.7476(10)$ & 14.55 & \\
$\beta, \circ$ & $115.195(5)$ & 114.8 & \\
$V, \AA^{3}$ & $930.42(12)$ & 908.38 & \\
$M \cdots \mathrm{F}$ & $2.64(11)$ & 2.61 & \\
& $2.87(12)$ & 2.98 & \\
Os-F & $1.72(9)$ & 1.87 & $1.82(3)$ \\
& $2.08(10)$ & 1.92 & $86(1)$ \\
F-Os-F\# & $82(4)$ & 87.9 & $94(1)$ \\
\hline
\end{tabular}

* Minimal and maximal values for distances and angles are given. F\# denotes another fluorine atom in equivalent to $\mathrm{F}$.

Table 2. Crystallographic details of the characterized compounds.

\begin{tabular}{|c|c|c|c|}
\hline Parameter & $\mathrm{Ba}\left(\mathrm{OsF}_{6}\right)_{2}$ & $\mathrm{BaOsF}_{6}$ & $\mathrm{Ba}\left(\mathrm{OsF}_{6}\right)_{2} \cdot 6 \mathrm{H}_{2} \mathrm{O}$ \\
\hline Color and appearance & Pale-pink powder & Colorless needles & Colorless blocks \\
\hline $\mathrm{M} / \mathrm{g} \cdot \mathrm{mol}^{-1}$ & 745.77 & 441.55 & 853.86 \\
\hline Crystal system & Monoclinic & Rhombohedral & Triclinic \\
\hline Space group & $P 2_{1} / c$ (No. 14 ) & $R \overline{3}$ (No. 148) & $P \overline{1}($ No. 2$)$ \\
\hline$a / \AA$ & $6.4599(4)$ & $7.3286(10)$ & $8.9967(5)$ \\
\hline$\alpha /{ }^{\circ}$ & 90 & 90 & $84.653(5)$ \\
\hline$\beta /{ }^{\circ}$ & $115.195(5)$ & 90 & $64.629(4)$ \\
\hline$\gamma /{ }^{\circ}$ & 90 & 120 & $64.273(4)$ \\
\hline$V / \AA^{3}$ & $930.42(12)$ & $337.95(12)$ & $741.55(8)$ \\
\hline Z & 4 & 3 & 2 \\
\hline$\rho_{\text {calc }} / \mathrm{g} \cdot \mathrm{cm}^{-3}$ & 5.324 & 6.509 & 3.824 \\
\hline$R_{\mathrm{int}}, R_{\sigma}$ & - & $0.0247,0.0229$ & $0.0397,0.0358$ \\
\hline$R_{\mathrm{p}}, w R_{\mathrm{p}}$ & $0.0343,0.0492$ & - & - \\
\hline$R\left(F^{2}\right)$ (all data), $w R\left(F^{2}\right)$ (all data) & $0.0365,0.0468$ & $0.0198,0.0390$ & $0.0336,0.0383$ \\
\hline$S$ (all data) & - & 1.050 & 0.832 \\
\hline No. of data points, parameters, constraints, restraints & $4356,85,0,0$ & $258,14,0,0$ & $5088,227,0,0$ \\
\hline $2 \theta$ range measured (min; $\max ;$ increment) & $10,75.325,0.015$ & $8.53,63.69,-$ & $4.44,63.80,-$ \\
\hline $2 \theta$ range refined (min; max) & $10,75.325,0.015$ & $8.53,63.69,-$ & $4.44,63.80,-$ \\
\hline$\Delta \rho_{\max }, \Delta \rho_{\min } / \mathrm{e} \cdot \AA^{-3}$ & - & $1.077,-1.451$ & $1.323,-1.195$ \\
\hline
\end{tabular}

We recorded the IR spectrum of $\mathrm{Ba}\left(\mathrm{OsF}_{6}\right)_{2}$ in the range from 4000 to circa $360 \mathrm{~cm}^{-1}$. We observe no vibrations in the range down to $1500 \mathrm{~cm}^{-1}$, which shows the purity of the compound. For further details of the band assignment in the region from 1500 to $360 \mathrm{~cm}^{-1}$, see the Supporting Information, Figure S1 and Table S1. 
Additionally, we measured the ${ }^{1} \mathrm{H}$ and ${ }^{19} \mathrm{~F}$ NMR spectra (Figure S2) of the compound dissolved in anhydrous hydrogen fluoride at room temperature. Due to the paramagnetic properties of $\operatorname{osmium}(\mathrm{V})$, the signals are broadened and the chemical shift is unpredictable in NMR spectroscopy [31]. The paramagnetic shift of the solvent additionally gives information on the interaction of $\mathrm{Ba}\left(\mathrm{OsF}_{6}\right)_{2}$ with the solvent.

The proton signal of $\mathrm{HF}$ in the ${ }^{1} \mathrm{H}$ NMR spectrum of a $\mathrm{Ba}\left(\mathrm{OsF}_{6}\right)_{2}$ solution in anhydrous hydrogen fluoride (Figure 4) was observed at $19.93 \mathrm{ppm}\left(\omega_{1 / 2}=12.6 \mathrm{~Hz}\right)$. This is a downfield shift of $10.55 \mathrm{ppm}$ when compared to neat anhydrous hydrogen fluoride which we observed at $8.38 \mathrm{ppm}\left(\omega_{1 / 2}=2.9 \mathrm{~Hz}\right)$. This trend is also observed in the ${ }^{19} \mathrm{~F}$ NMR spectrum (Figure 5) where the fluorine signal of HF was observed at $-176.32 \mathrm{ppm}\left(\omega_{1 / 2}=79.0 \mathrm{~Hz}\right)$, which is a downfield shift of $22 \mathrm{ppm}$ as compared to neat hydrogen fluoride $\left(-198.32 \mathrm{ppm}, \omega_{1 / 2}=12.0 \mathrm{~Hz}\right)$. This distinct paramagnetic down field shift is indicative for a considerable interaction of the paramagnetic $\mathrm{OsF}_{6}{ }^{-}$-moiety with the solvent, and it is expected if the osmium $(\mathrm{V})$-anion is in solution. The observed chemical shift of neat anhydrous hydrogen fluoride in the ${ }^{1} \mathrm{H}$ and ${ }^{19} \mathrm{~F}$ NMR spectra are in good agreement with literature values [32].

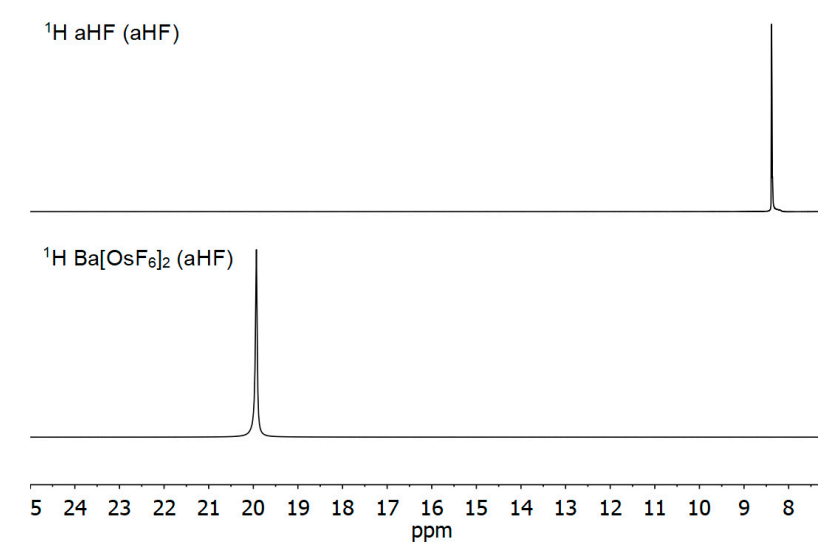

Figure $4 .{ }^{1} \mathrm{H}$ NMR spectra of neat anydrous $\mathrm{HF}$ (top) and anhydrous $\mathrm{HF}$ with $\mathrm{Ba}\left(\mathrm{OsF}_{6}\right)_{2}$ (bottom).

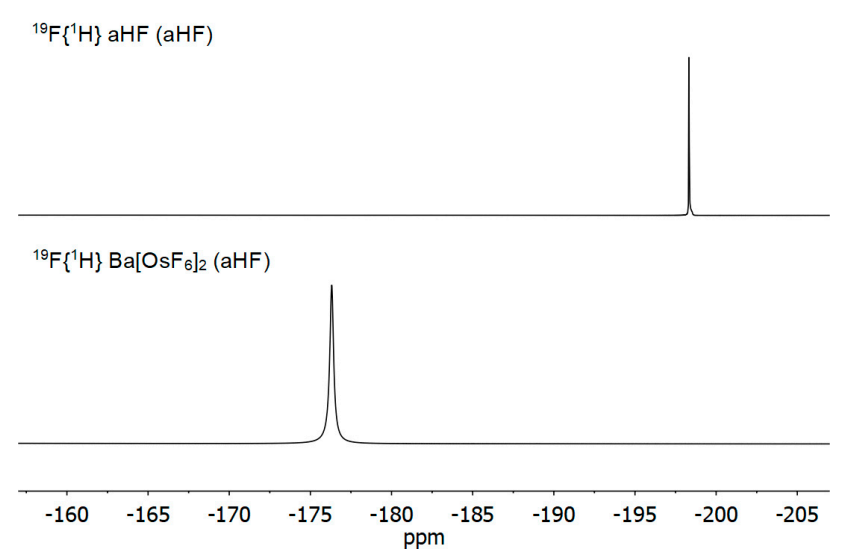

Figure 5. ${ }^{19} \mathrm{~F}$ NMR spectrum of anhydrous $\mathrm{HF}$ (top) and $\mathrm{Ba}\left(\mathrm{OsF}_{6}\right)_{2}$ in anhydrous $\mathrm{HF}$ (bottom).

While in the ${ }^{1} \mathrm{H}$ NMR spectrum of $\mathrm{Ba}\left(\mathrm{OsF}_{6}\right)_{2}$ solutions in $\mathrm{HF}$, no further signal was observed -as would be expected—one additional signal at $149.03 \mathrm{ppm}$, with a very broad line width $\left(\omega_{1 / 2}=131.6 \mathrm{~Hz}\right)$ was observed in the ${ }^{19} \mathrm{~F}$ NMR spectrum (Figure 6). This signal is assigned to the $\mathrm{OsF}_{6}{ }^{-}$-anion and indicates that only one species is present in solution. Therefore, the anions are solvent separated and do not interact with each other. 


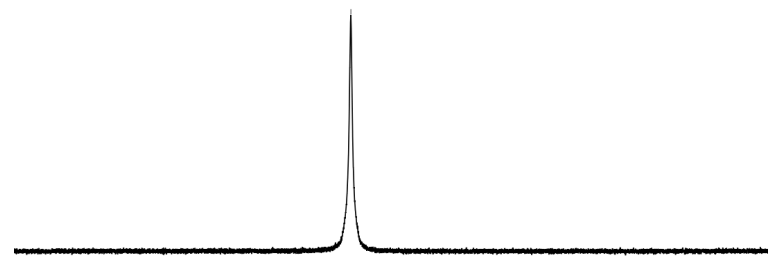

$185180175170165160155150 \begin{gathered}145140135130125120115 \\ \mathrm{ppm}\end{gathered}$

Figure 6. A part of ${ }^{19} \mathrm{~F} \mathrm{NMR}$ spectrum of $\mathrm{Ba}\left(\mathrm{OsF}_{6}\right)_{2}$ in anhydrous $\mathrm{HF}$ showing the $\mathrm{OsF}_{6}{ }^{-}$signal.

\subsection{Barium Hexafluoridoosmate(IV)}

As mentioned above, we obtained $\mathrm{BaOsF}_{6}$ in the form of colorless crystals with an impurity of the yet unidentified black powder. One of the crystals was selected under perfluorinated oil and was mounted on the goniometer using the MiTeGen MicroLoops ${ }^{\mathrm{TM}}$ system.

By single crystal X-ray diffraction we observed that barium hexafluoridoosmate(IV) crystallizes in the trigonal centered space group type $R \overline{3}$ (No. 148) with the cell parameters $a=7.3286(10)$, $c=7.2658(15) \AA, V=337.95(12) \AA^{3}, Z=3$ at $100 \mathrm{~K}$ and, therefore, isotypic to $\mathrm{BaRuF}_{6}[8,33]$ and BaIrF $_{6}[8,34]$. The crystal structure of $\mathrm{BaOsF}_{6}$ is shown in Figure 7 . A section of its crystal structure showing one formula unit is given in Figure 8.

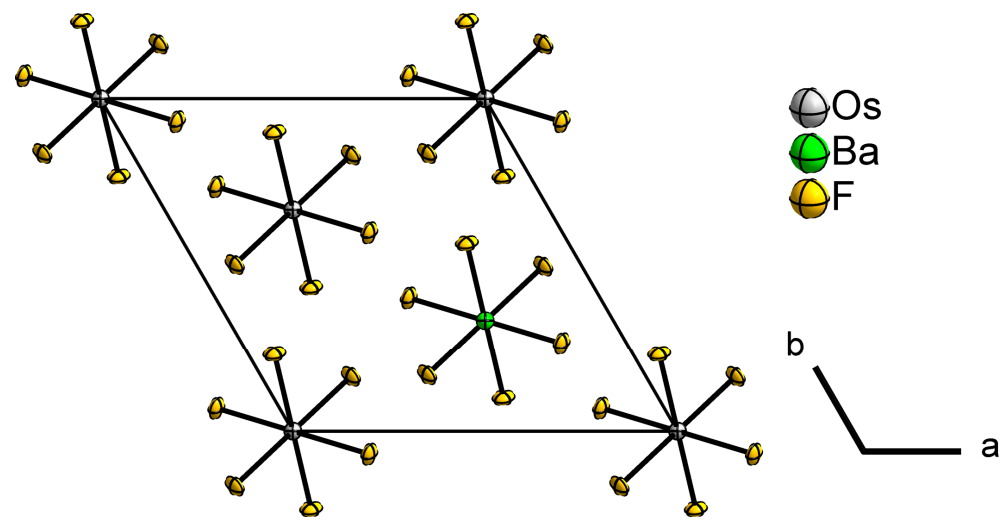

Figure 7. The crystal structure of $\mathrm{BaOsF}_{6}$ (projection along $c$-axis). Displacement ellipsoids are shown at $70 \%$ probability level at $100 \mathrm{~K}$.

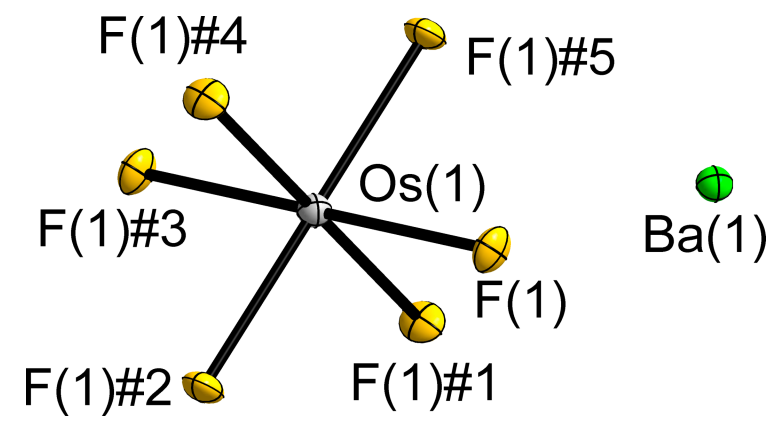

Figure 8. Formula unit of $\mathrm{BaOsF}_{6}$. Displacement ellipsoids are shown at $70 \%$ probability at $100 \mathrm{~K}$. 
The barium ion occupies the special $3 b$ Wyckoff position and is coordinated by twelve fluorine atoms, which stem from eight $\mathrm{OsF}_{6}{ }^{2-}$ anions. The resulting coordination polyhedron is close to a cuboctahedron. The Ba $\cdots$ F distances are 2.773(3) and 2.870(3) A.

Each osmium atom resides on the special $3 a$ Wyckoff position $(\overline{3})$ and is coordinated by six fluorine atoms (each on the general $18 \mathrm{f}$ position), resulting in an arrangement that is very similar to an octahedron ( $S_{6}$-symmetry). The Os-F bond length is $1.937(3) \AA$, the F-Os-F\# angles are $85.68(12)$, and $94.32(12)^{\circ}$. Similar values are reported for the isotypic $\mathrm{BaIrF}_{6}$ with the $\mathrm{Ir}-\mathrm{F}$ bond being 1.936(4) $\AA$ and F-Ir-F\# angles of $85.93(17)$ and $94.07(16)^{\circ}$. The experimentally determined and calculated cell parameters, bond lengths, and angles of $\mathrm{BaOsF}_{6}$ are given in Table 2. As to the best of our knowledge, no other compound containing a $\mathrm{OsF}_{6}{ }^{2-}$ anion has been structurally characterized so far, we compare distances and angles with the isotypic $\mathrm{BaIrF}_{6}$ (Table 3).

Table 3. Selected crystallographic data for $\mathrm{BaOsF}_{6}$ and $\mathrm{BaIrF}_{6}$ [34].

\begin{tabular}{cccc}
\hline \multirow{2}{*}{ Value } & \multicolumn{2}{c}{ BaOsF $_{\mathbf{6}}$} & \multirow{2}{*}{ BaIrF $_{\mathbf{6}}$} \\
\cline { 2 - 3 } & Exp. & DFT-PBE0 & \\
\hline$a, \AA$ & $7.3286(10)$ & 7.21 & $7.3965(5)$ \\
$c, \AA$ & $7.2658(15)$ & 7.33 & $7.2826(7)$ \\
$V, \AA^{3}$ & $337.95(12)$ & 330.21 & $345.04(6)$ \\
& $2.773(3)$ & 2.6 & $2.800(4)$ \\
$\mathrm{Ba} \cdots \mathrm{F}$ & $2.870(3)$ & 2.98 & $2.882(4)$ \\
$M-\mathrm{F}$ & $1.937(3)$ & 1.96 & $1.936(4)$ \\
$\mathrm{F}-\mathrm{M}-\mathrm{F} \#$ & $85.93(17)$ & 82.7 & $85.9(2)$ \\
& $94.07(16)$ & 97.3 & $94.1(2)$ \\
\hline
\end{tabular}

In order to identify the nature of the black powder that accompanies the formation of $\mathrm{BaOsF}_{6}$, we collected a powder X-ray diffraction pattern of the mixture. However, as it is seen from Figure 9, the pattern contains only the reflections of barium hexafluoridoosmate(IV), indicating an amorphous nature of the other phase.

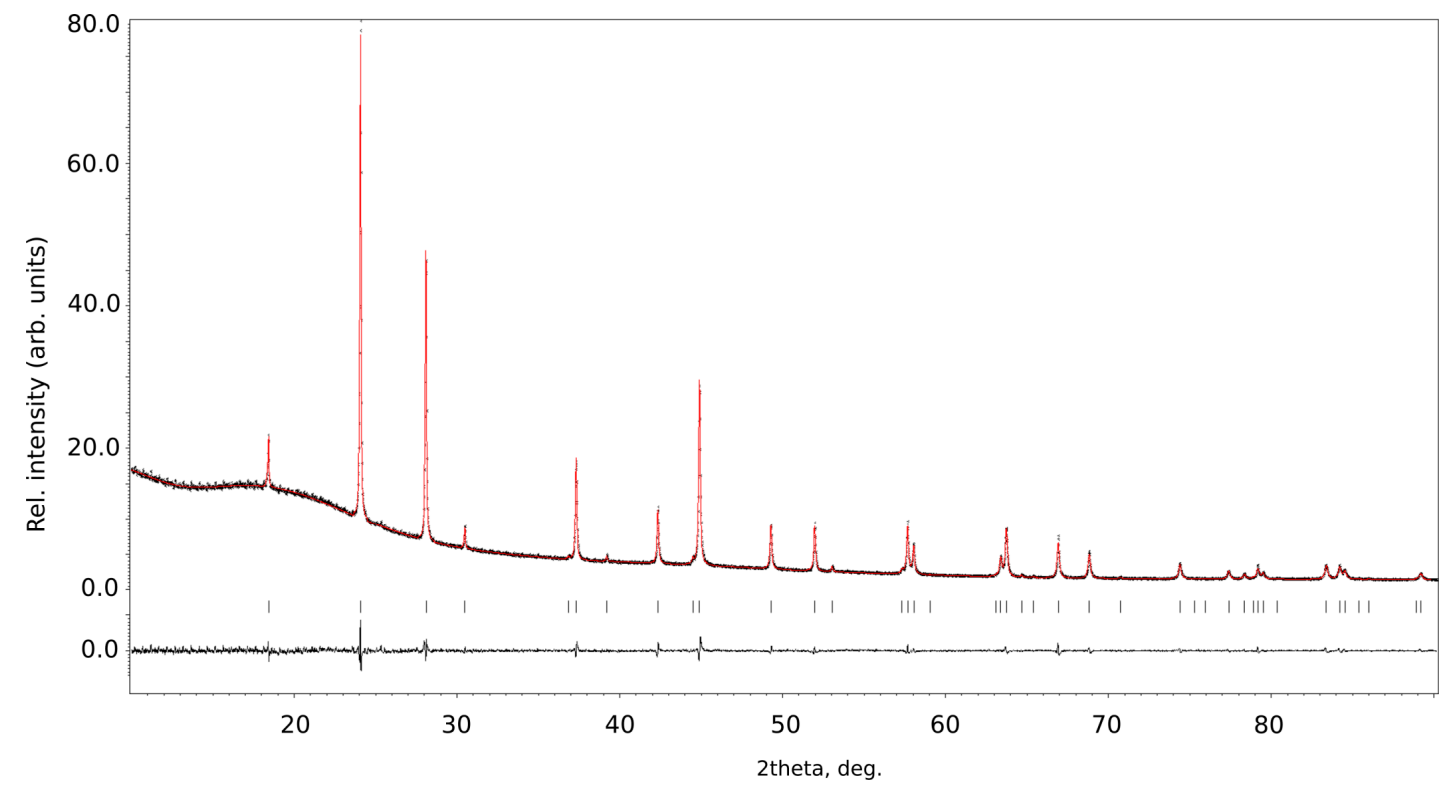

Figure 9. Powder X-ray diffraction pattern (at $293 \mathrm{~K}$ ) of $\mathrm{BaOsF}_{6}$ : the experimental data (black crosses), the Le Bail profile (red), and the differential profile (bottom, black). The calculated reflection positions for $\mathrm{BaOsF}_{6}$ are shown as black ticks. $R_{\mathrm{p}}=0.0189, w R_{\mathrm{p}}=0.0264$. 
An additional investigation by means of IR spectroscopy (Figure 10) did not show the presence of any characteristic vibrational modes, e.g., of the $\mathrm{OH}^{-}$group, indicating that the black powder is a relatively simple compound. The investigations on the identification of this phase are ongoing. Currently, we think that the phase may be osmium dioxide (see Reaction 2), which is known to be formed in amorphous state from the reduction of aqueous solutions of $\mathrm{OsO}_{4}$ [35].

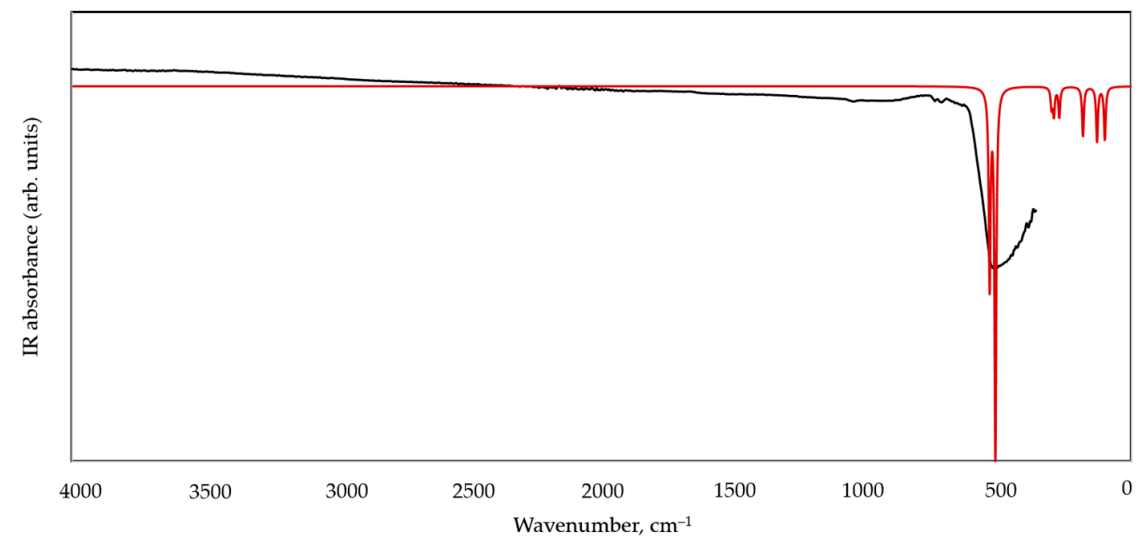

Figure 10. IR spectra of $\mathrm{BaOsF}_{6}$ : experimentally observed (black) and calculated with DFT-PBE0 (red).

Unfortunately, the compound is insoluble in anhydrous HF, so no solution NMR spectrum could be obtained.

\subsection{A barium Hexafluoridoosmate( $V$ ) Solvate of $\mathrm{BrF}_{3}$}

In an attempt to grow single crystals of $\mathrm{Ba}\left(\mathrm{OsF}_{6}\right)_{2}$, we tried to use bromine trifluoride as a solvent. Upon partial evaporation of $\mathrm{BrF}_{3}$ and the subsequent cooling of the resulting solution down to room temperature, big pale-green prismatic crystals were obtained. One crystal was selected under perfluorinated oil using a polarizing light-optical microscope and mounted on the goniometer.

The obtained compound crystallizes in a primitive monoclinic cell with the cell parameters $a=15.539(3), b=37.029(7), c=15.722(3) \AA, \beta=90.10(3)^{\circ}$, and $V=9046(3) \AA^{3}$ at $100 \mathrm{~K}$. The tentative space group type is $P 2_{1} / n$ (No. 14). The structure solution and refinement did not lead to a chemically plausible model. Due to the $\beta$-angle being so close to $90^{\circ}$, we also attempted structure solutions in the orthorhombic crystal system and then using various twin refinements. However, the structure models obtained were not satisfactory. The refinement of the structure in one of the maximal translationengleiche subgroups of $P 2_{1} / n$, namely $P n, P 2_{1}$, and $P \overline{1}$, led to no substantial improvement of the structural model. The investigations on the crystal structure of this solvate are ongoing and the results will be reported elsewhere.

\subsection{A Barium Hexafluoridoosmate(V) Solvate of Hydrogen Fluoride}

Anhydrous hydrogen fluoride (aHF) was used as the next solvent to obtain single crystals of $\mathrm{Ba}\left(\mathrm{OsF}_{6}\right)_{2}$. Upon dissolving $\mathrm{Ba}\left(\mathrm{OsF}_{6}\right)_{2}$ in $\mathrm{aHF}$, a clear red solution was obtained. When the solvent was partially evaporated, red-pink crystals were formed. The crystals were selected directly out of aHF and mounted under perfluorinated oil. After solving the crystal structure, we identified this new compound preliminary as " $\mathrm{Ba}\left(\mathrm{OsF}_{6}\right)_{2} \cdot \mathrm{HF}$.

Barium bis(hexafluoridoosmate $(\mathrm{V}))$-hydrogen fluoride $(1 / 1)$ crystallizes in the orthorhombic crystal system. First, we obtained the lattice parameters $a=10.9127(12), b=11.5853(11)$, and $c=$ 15.900(2) $\AA, V=2010.2(4) \AA^{3}$ at $100 \mathrm{~K}$, and the space group type Pbcn (No. 60) was established. However, the structure model showed rather large displacement parameters for the fluorine ligands bound to the Os atom. As we could not resolve the disorder, we checked the reciprocal space for additional information and observed statistically significant superstructure reflections leading to 
the lattice parameters $a=21.8173(7), b=31.7637(15), c=11.8742(3) \AA$, and $V=8020.9(4) \AA^{3}$ at $100 \mathrm{~K}$. However, all of our refinements in the larger unit cell led to unsatisfactory results. Currently, the crystal structure of the compound is still under investigation and will be reported elsewhere.

\subsection{Barium Hexafluoridoosmate(V) Hexahydrate}

We used water as the last choice of solvents in this study. Despite that $\mathrm{Ba}\left(\mathrm{OsF}_{6}\right)_{2}$ is hydrolyzed in water, this process is not instantaneous giving the chance to recrystallize the substance. However, the obtained crystals belong to another new compound: barium hexafluoridoosmate $(\mathrm{V})$ hexahydrate, $\mathrm{Ba}\left(\mathrm{OsF}_{6}\right)_{2} \cdot 6 \mathrm{H}_{2} \mathrm{O}$.

Barium bis(hexafluoridoosmate $(\mathrm{V}))$ hexahydrate crystallizes in the triclinic space group type $P \overline{1}$ (No. 2) with cell parameters $a=8.9967(5), b=9.9840(6), c=10.2088(6) \AA, \alpha=84.653(5)^{\circ}, \beta=64.629(4)^{\circ}$, $\gamma=64.273(4)^{\circ}, V=741.55(8) \AA^{3}$, and $\mathrm{Z}=2$ at $100 \mathrm{~K}$. The crystal structure of $\mathrm{Ba}\left(\mathrm{OsF}_{6}\right)_{2} \cdot 6 \mathrm{H}_{2} \mathrm{O}$ is shown in Figure 11; a section of the crystal structure showing the surroundings of the barium cation is shown in Figure 12.

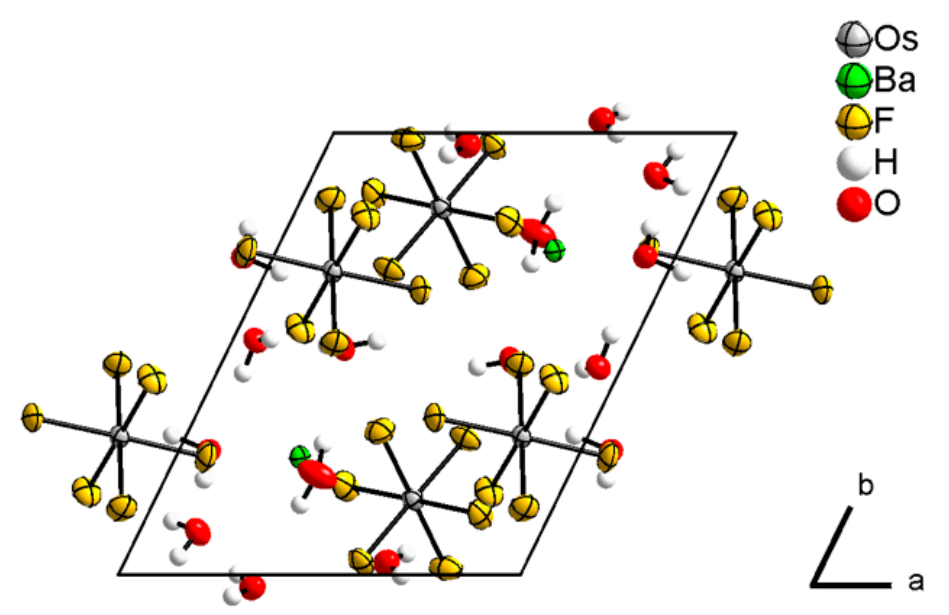

Figure 11. The crystal structure of $\mathrm{Ba}\left(\mathrm{OsF}_{6}\right)_{2} \cdot 6 \mathrm{H}_{2} \mathrm{O}$ (projection along $c$-axis). Displacement ellipsoids are shown at $70 \%$ probability level at $100 \mathrm{~K}$. All the non-hydrogen atoms are shown anisotropic, hydrogen atoms are shown with arbitrary radii.

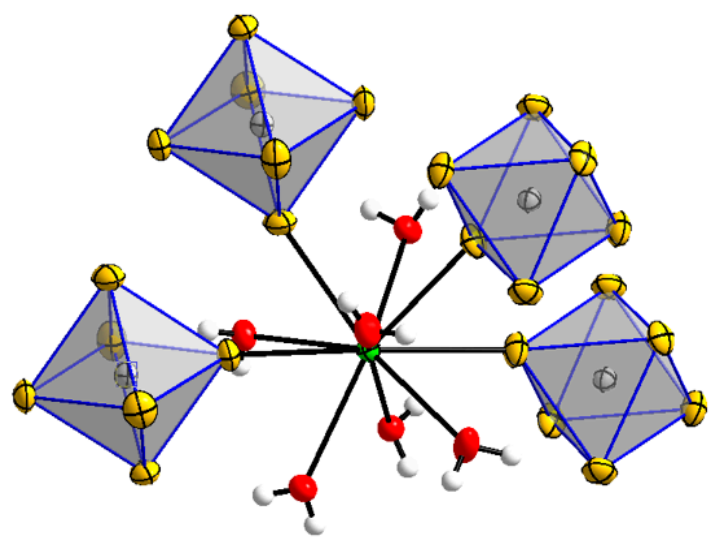

Figure 12. Fragment of the crystal structure of $\mathrm{Ba}\left(\mathrm{OsF}_{6}\right)_{2} \cdot 6 \mathrm{H}_{2} \mathrm{O}$ showing the coordination of $\mathrm{OsF}_{6}{ }^{-}$ and $\mathrm{H}_{2} \mathrm{O}$ around $\mathrm{Ba}^{2+}$. Displacement ellipsoids are shown at $70 \%$ probability level at $100 \mathrm{~K}$. All non-hydrogen atoms are shown anisotropic, hydrogen atoms are shown with arbitrary radii. 
All atoms in $\mathrm{Ba}\left(\mathrm{OsF}_{6}\right)_{2} \cdot 6 \mathrm{H}_{2} \mathrm{O}$ occupy the general $2 i$ Wyckoff position. The barium cation has the coordination number 10 and is coordinated by six oxygen atoms and four fluorine atoms. The resulting coordination polyhedron is a bicapped square antiprism. The Ba $\cdots \mathrm{O}$ distances lie within the internal

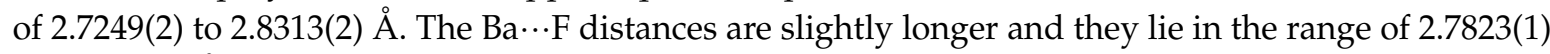
to $2.9324(2) \AA$.

The $\mathrm{OsF}_{6}{ }^{-}$anions are very close to the octahedral geometry: the Os-F bond lengths are 1.8607(1) to $1.8823(1) \AA$ and F-Os-F\# angles are 88.876(4) to $90.924(4)^{\circ}$. The neighboring anions are linked together through the water molecules by weak hydrogen bonds: the shortest $\mathrm{O} \cdots \mathrm{F}$ distance equals 2.8069(1) A. The crystallographic details of $\mathrm{Ba}\left(\mathrm{OsF}_{6}\right)_{2} \cdot 6 \mathrm{H}_{2} \mathrm{O}$ are given in Table 2 .

\section{Conclusions}

In this work, we have synthesized and structurally characterized for the first time two alkaline-earth metal hexafluoridoosmates: $\mathrm{Ba}\left(\mathrm{OsF}_{6}\right)_{2}$ and $\mathrm{BaOsF}_{6}$. The compounds contain spatially isolated $\mathrm{OsF}_{6}{ }^{-}$(or $\mathrm{OsF}_{6}{ }^{2-}$ respectively) anions with their symmetry close to $\mathrm{O}_{\mathrm{h}}$. In an attempt to grow single crystals of $\mathrm{Ba}\left(\mathrm{OsF}_{6}\right)_{2}$, we obtained three new solvates depending on the used solvent: $\mathrm{Ba}\left(\mathrm{OsF}_{6}\right)_{2} \cdot 3 \mathrm{BrF}_{3}, \mathrm{Ba}\left(\mathrm{OsF}_{6}\right)_{2} \cdot \mathrm{HF}$, and $\mathrm{Ba}\left(\mathrm{OsF}_{6}\right)_{2} \cdot 6 \mathrm{H}_{2} \mathrm{O}$, which were also characterized.

Supplementary Materials: The following are available online at www.mdpi.com/2073-4352/8/1/11/s1: Figure S1: IR spectra of $\mathrm{Ba}\left(\mathrm{OsF}_{6}\right)_{2}$ : experimentally observed (black) and calculated with DFT-PBE0 (red), Figure S2: ${ }^{19} \mathrm{~F}$ NMR spectrum of $\mathrm{Ba}\left(\mathrm{OsF}_{6}\right)_{2}$ in anhydrous HF, Table S1: Region assignment for the theoretical IR spectrum of $\mathrm{Ba}\left(\mathrm{OsF}_{6}\right)_{2}$, Basis sets.

Acknowledgments: We thank the Deutsche Forschungsgemeinschaft and the Deutscher Akademischer Austauschdienst for funding. Florian Kraus thanks the DFG for a Heisenberg professorship. Antti J. Karttunen thanks the Academy of Finland for funding (grant 294799) and CSC, the Finnish IT Center for Science, for computational resources. This work is supported by Russian Governmental Program 'Nauka' N 4.3967.2017/PCh.

Author Contributions: Sergei I. Ivlev, Roman V. Ostvald and Florian Kraus conceived and designed the experiments; Sergei I. Ivlev performed the experiments; Sergei I. Ivlev and Antti J. Karttunen performed the calculations; Magnus R. Buchner measured the NMR spectra; Sergei I. Ivlev, Antti J. Karttunen, Magnus R. Buchner, Roman V. Ostvald and Florian Kraus analyzed the data; Sergei I. Ivlev and Florian Kraus wrote the paper.

Conflicts of Interest: The authors declare no conflict of interest.

\section{References}

1. Hepworth, M.A.; Robinson, P.L.; Westland, G.J. Complex fluorides of iridium and osmium. J. Chem. Soc. 1954, 4269-4275. [CrossRef]

2. Peacock, R.D.; Sharp, D.W.A. 554. The infrared spectra of alkali salts of complex fluoro-acids. J. Chem. Soc. 1959, 2762-2767. [CrossRef]

3. Burns, R.C.; O'Donnell, T.A. Reactivity of Transition Metal Fluorides-X. Oxidation-Reduction reactions of rhenium, osmium and iridium hexafluorides. J. Inorg. Nucl. Chem. 1980, 42, 1285-1291. [CrossRef]

4. Hepworth, M.A.; Robinson, P.L.; Westland, G.J. 119. Complex fluorides of quadrivalent osmium and iridium and the corresponding free acids. J. Chem. Soc. 1958, 611-613. [CrossRef]

5. Adams, D.M.; Gebbie, H.A. Absorption spectra of some inorganic complex halides by far infra-red interferometry. Spectrochim. Acta 1963, 19, 925-930. [CrossRef]

6. Allen, G.C.; Al-Mobarak, R.; El-Sharkawy, G.A.M.; Warren, K.D. Electronic spectra of the hexahalo anions of osmium(IV) and iridium(IV). Inorg. Chem. 1972, 11, 787-796. [CrossRef]

7. Kemmitt, R.D.W.; Russell, D.R.; Sharp, D.W.A. 844. The structural chemistry of complex fluorides of general formula $\mathrm{A}^{\mathrm{I}} \mathrm{B}^{\mathrm{V}} \mathrm{F}_{6}$. J. Chem. Soc. 1963, 4408-4413. [CrossRef]

8. Hepworth, M.A.; Jack, K.H.; Westland, G.J. Structures of complex fluorides-I: Potassium hexafluoro-osmate(V), $\mathrm{KOsF}_{6}$. J. Inorg. Nucl. Chem. 1956, 2, 79-87. [CrossRef]

9. Graudejus, O.; Wilkinson, A.P.; Chacón, L.C.; Bartlett, N. M-F Interatomic Distances and Effective Volumes of Second and Third Transition Series $\mathrm{MF}_{6}{ }^{-}$and $\mathrm{MF}_{6}{ }^{2-}$ Anions. Inorg. Chem. 2000, 39, 2794-2800. [CrossRef] [PubMed] 
10. Mitkin, V.N. Fluorination of iridium metal and its application possibilities in the synthesis, analysis and recovery technology for secondary raw materials (review). In Proceedings of the International Symposium TMS-2000, Nashville, TN, USA, 12-16 March 2000; pp. 377-390.

11. Ivlev, S.; Woidy, P.; Kraus, F.; Gerin, I.; Ostvald, R. Tetrafluorobromates for Urban Mining of Noble Metals: A Case Study on Iridium Metal. Eur. J. Inorg. Chem. 2013, 2013, 4984-4987. [CrossRef]

12. Mitkin, V.N. Physical-chemical basis for application of fluoroxidants in noble metal analytical chemistry. Spectrochim. Acta Part B At. Spectrosc. 2001, 56, 135-175. [CrossRef]

13. Mitkin, V.N. Gold and Platinum-Group Element Analysis of Geochemical and Platinum Reference Materials Using Fluoroxidation Decomposition. Geostand. Newsl. 2000, 24, 157-170. [CrossRef]

14. Pedersen, K.S.; Woodruff, D.N.; Singh, S.K.; Tressaud, A.; Durand, E.; Atanasov, M.; Perlepe, P.; Ollefs, K.; Wilhelm, F.; Mathonière, C.; et al. $\left[\mathrm{OsF}_{6}\right]^{\mathrm{x}-}$ : Molecular Models for Spin-Orbit Entangled Phenomena. Chemistry 2017, 23, 11244-11248. [CrossRef] [PubMed]

15. X-Area, v1.35; STOE \& Cie GmbH: Darmstadt, Germany, 2013.

16. Sheldrick, G.M. SHELXT-Integrated space-group and crystal-structure determination. Acta Crystallogr. Sect. A Found. Adv. 2015, 71, 3-8. [CrossRef] [PubMed]

17. Sheldrick, G.M. Crystal structure refinement with SHELXL. Acta Crystallogr. Sect. C Struct. Chem. 2015, 71, 3-8. [CrossRef] [PubMed]

18. WinXPOW; Stoe \& Cie GmbH: Darmstadt, Germany, 2011.

19. Petricek, V.; Dusek, M.; Palatinus, L. Jana 2006. The Crystallographic Computing System; Institute of Physics: Praha, Czech Republic, 2006.

20. Palatinus, L.; Chapuis, G. SUPERFLIP-A computer program for the solution of crystal structures by charge flipping in arbitrary dimensions. J. Appl. Crystallogr. 2007, 40, 786-790. [CrossRef]

21. OPUS; Bruker Optik GmbH: Ettlingen, Germany, 2009.

22. Dovesi, R.; Orlando, R.; Erba, A.; Zicovich-Wilson, C.M.; Civalleri, B.; Casassa, S.; Maschio, L.; Ferrabone, M.; De La Pierre, M.; D'Arco, P.; et al. CRYSTAL14: A program for the ab initio investigation of crystalline solids. Int. J. Quantum Chem. 2014, 114, 1287-1317. [CrossRef]

23. Dovesi, R.; Saunders, V.R.; Roetti, C.; Orlando, R.; Zicovich-Wilson, C.M.; Pascale, F.; Civalleri, B.; Doll, K.; Harrison, N.M.; Bush, I.J.; et al. CRYSTAL14 User's Manual; University of Torino: Torino, Italy, 2014.

24. Perdew, J.P.; Burke, K.; Ernzerhof, M. Generalized Gradient Approximation Made Simple. Phys. Rev. Lett. 1996, 77, 3865-3868. [CrossRef] [PubMed]

25. Adamo, C.; Barone, V. Toward reliable density functional methods without adjustable parameters: The PBE0 model. J. Chem. Phys. 1999, 110, 6158-6170. [CrossRef]

26. Weigend, F.; Ahlrichs, R. Balanced basis sets of split valence, triple zeta valence and quadruple zeta valence quality for H to Rn: Design and assessment of accuracy. Phys. Chem. Chem. Phys. 2005, 7, 3297-3305. [CrossRef] [PubMed]

27. Monkhorst, H.J.; Pack, J.D. Special points for Brillouin-zone integrations. Phys. Rev. B 1976, 13, 5188-5192. [CrossRef]

28. Pascale, F.; Zicovich-Wilson, C.M.; López Gejo, F.; Civalleri, B.; Orlando, R.; Dovesi, R. The calculation of the vibrational frequencies of crystalline compounds and its implementation in the CRYSTAL code. J. Comput. Chem. 2004, 25, 888-897. [CrossRef] [PubMed]

29. Zicovich-Wilson, C.M.; Pascale, F.; Roetti, C.; Saunders, V.R.; Orlando, R.; Dovesi, R. Calculation of the vibration frequencies of alpha-quartz: The effect of Hamiltonian and basis set. J. Comput. Chem. 2004, 25, 1873-1881. [CrossRef] [PubMed]

30. Maschio, L.; Kirtman, B.; Orlando, R.; Rèrat, M. Ab initio analytical infrared intensities for periodic systems through a coupled perturbed Hartree-Fock/Kohn-Sham method. J. Chem. Phys. 2012, 137, 204113. [CrossRef] [PubMed]

31. Schwarzhans, K.E. NMR Spectroscopy of Paramagnetic Complexes. Angew. Chem. Int. Ed. Engl. 1970, 9, 946-953. [CrossRef]

32. Shamir, J.; Netzer, A.N.M.R. Studies of Anhydrous Hydrogen Fluoride Solutions. Can. J. Chem. 1973, 51, 2676-2684. [CrossRef]

33. Weise, E.; Klemm, W. Fluorokomplexe des Rutheniums. Z. Anorg. Allg. Chem. 1955, 279, 74-83. [CrossRef] 
34. Smolentsev, A.I.; Gubanov, A.I.; Danilenko, A.M. Three hexafluoridoiridates(IV), $\mathrm{Ca}\left[\operatorname{IrF}_{6}\right] \cdot 2 \mathrm{H}_{2} \mathrm{O}_{\text {, }}$ $\mathrm{Sr}\left[\mathrm{IrF}_{6}\right] \cdot 2 \mathrm{H}_{2} \mathrm{O}$ and $\mathrm{Ba}\left[\mathrm{IrF}_{6}\right]$. Acta Crystallogr. C 2007, 63, i99-i101. [CrossRef] [PubMed]

35. Boman, C.E. Precision Determination of the Crystal Structure of Osmium Dioxide. Acta Chem. Scand. 1970, 24, 123-128. [CrossRef] 